\title{
Proposta e Análise de Dispositivo para Otimização do Destacamento da Gota na Soldagem MIG/MAG
}

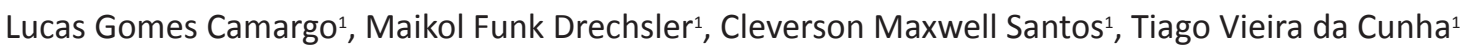 \\ 1 Universidade Federal de Santa Catarina - UFSC, Campus Joinville, Joinville, SC, Brasil.
}

Recebido: 22 Dez., 2015

Aceito: 07 Mar., 2016

E-mail: lucas.g.c@grad.ufsc.br (LGC)
Este é um artigo publicado em acesso aberto (Open Access) sob a licença Creative Commons Attribution Non-Commercial, que permite uso, distribuição e reprodução em qualquer meio, sem restriçōes desde que sem fins comerciais e que 0 trabalho original seja corretamente citado.
Resumo: Diversas forças atuam na soldagem MIG/MAG durante a transferência da gota fundida presente na extremidade do arame-eletrodo à poça de fusão, as quais variam de acordo com o modo de transferência adotado. No modo globular, o destacamento da gota ocorre quando a sua força peso supera a tensão superficial produzindo gotas maiores que provocam maior instabilidade durante sua transferência. Já no modo goticular, os altos valores de corrente intensificam a atuação da força de Lorentz. Esta força magnética proporciona o desprendimento da gota ainda em pequenas dimensões, resultando numa maior estabilidade. Entretanto, este modo de transferência caracteriza-se por um relativo grande aporte de energia, o que inviabiliza uniões de chapas finas ou fora de posição. Busca-se então neste trabalho, analisar a viabilidade da utilização de uma força magnética externa que auxilie o processo de destacamento da gota e propor um dispositivo para esta finalidade. O intuito é obter um modo de transferência semelhante ao goticular, porém, com baixos valores de corrente de soldagem sem, entretanto, a necessidade de emprego de fontes eletrônicas. Deste modo, espera-se obter uma maior estabilidade no processo aliada a uma menor quantidade de calor entregue a peça. Contudo, os resultados obtidos mostram a inviabilidade tecnológica quanto à utilização do dispositivo proposto, dada à necessidade de emprego de níveis de correntes extremamente elevados (da ordem de 100.000A) para sensibilizar a gota na ponta do eletrodo.

Palavras-chave: Transferência metálica; Indução eletromagnética; Força de Lorentz; MIG/MAG.

\section{Proposal and Analysis of Device to Optimization of Drop Detachment in MIG/MAG Welding}

\begin{abstract}
Several forces act in MIG/MAG welding during the transmission of the molten drop in the end of the wire electrode to the weld pool, which vary according to the transfer mode adopted. In the globular mode, the droplet detachment occurs when its weight overcomes the surface tension forces, thus producing larger droplets causing further instability during the transfer. In spray mode, the high current values intensify the action of Lorentz force. This magnetic force provides the detachment of the droplet even in small dimensions, resulting in increased stability. However, this transfer mode is characterized by a large power supply on, which prevents the union of thin or out of position sheets. This work analyzes the feasibility of using an external magnetic force to assist the drop detachment and propose a device for this purpose. The aim is to obtain a similar transfer mode to the spray, but in lower welding current values without the need of electronic sources. Thus, it is expected to achieve greater stability in the process combined to a smaller amount of heat delivered to the workpiece. Nevertheless, the results show the technological impossibility for the use of the proposed device, due to the need for extremely high current levels (around 100.000A) to sensitize the drop at the electrode tip.
\end{abstract}

Key-words: Metal transfer; Electromagnetic induction; Lorentz force; MIG/MAG.

\section{Introdução}

O processo MIG/MAG utiliza como fonte de calor um arco elétrico mantido entre um arame-eletrodo nu consumível, alimentado continuamente, e a peça de trabalho. Neste processo, quando da utilização de fontes convencionais, as principais variáveis de soldagem (tensão e corrente) são definidas a partir do ajuste da tensão e velocidade de alimentação do arame realizadas no citado equipamento. Os valores de tensão e corrente de soldagem resultantes são responsáveis, entre outros fatores, pela existência de diferentes modos de transferência metálica. Dentre estes se destacam os modos de transferência globular e goticular. Na transferência globular, tensões superiores no arco com baixa densidade de corrente conferem à gota um diâmetro maior que o do arame-eletrodo. 
Com a fusão do mesmo, o peso da gota cresce até um determinado valor onde a força gravitacional supera o efeito da tensão superficial no qual atua no sentido de manter a gota junto à extremidade do arame-eletrodo. Já no modo de transferência goticular, tem-se altos valores de corrente de soldagem e tensão de arco que são capazes de desprender do eletrodo gotas com diâmetro menor que o mesmo. Isso ocorre porque acima de uma determinada corrente de soldagem (corrente de transição), uma força eletromagnética (força de Lorentz) domina o processo. Esta força supera, portanto, a tensão superficial, proporcionando o desprendimento da gota da extremidade do arame-eletrodo antes que a mesma adquira um tamanho considerável. Contudo, apesar de proporcionar uma boa estabilidade do arco voltaico, dado ao fato de exigir altos valores de corrente, Kah et al. [1] apresenta que este modo de transferência é indicado somente para a soldagem de chapas grossas, devido ao maior aporte de calor entregue a peça. De um modo geral, o método de transferência goticular se destaca em relação ao globular pela excelente estabilidade do arco e qualidade do cordão de solda produzido, reduzindo a quantidade de respingos e aumentando a produtividade.

Durante o seu destacamento, a gota fundida presente na extremidade do arame-eletrodo está sob a ação de diversas forças. Segundo Scotti e Ponomarev [2], parâmetros como, por exemplo, composição do material, diâmetro do arame, natureza do gás de proteção e pressão ambiente possuem influência direta sobre a transferência metálica. Entretanto, é possível estudar o fenômeno da transferência metálica por um somatório de forças, modelo conhecido como Equilíbrio de Forças Estáticas. Segundo Brandi [3], existem divergências na literatura quanto à enumeração das forças que atuam na gota de metal líquido presente na extremidade do arame-eletrodo. Contudo, usualmente considera-se a presença da força gravitacional, força devido à tensão superficial, força de Lorentz (eletromagnética), força de arraste dos gases e força de expansão gasosa. Estas forças, e suas componentes, podem atuar tanto a favor do destacamento da gota, quanto na retenção da mesma na extremidade do arame-eletrodo. Deste modo, a gota se desprende do arame-eletrodo e segue para a poça de fusão quando o somatório das forças de destacamento superam as forças de retenção.

Ogino e Hirata [4] apresentam, a partir de simulação computacional, as magnitudes das principais forças que atuam sobre a gota. $O$ estudo foi realizado para os modos de transferência globular e goticular, com correntes de 170A e 250A respectivamente (Figura 1).

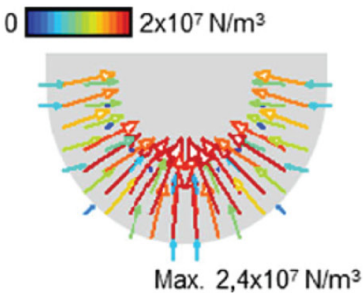

(i)Tensão superficial

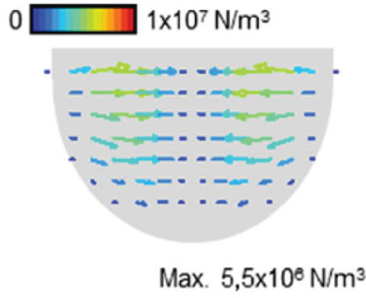

(ii)Força Eletromanética

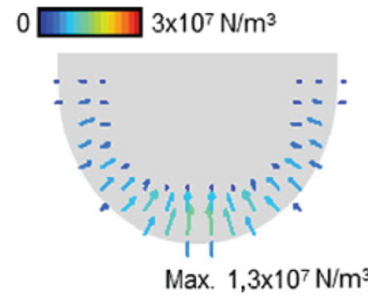

(iii) Força de expansão gasosa

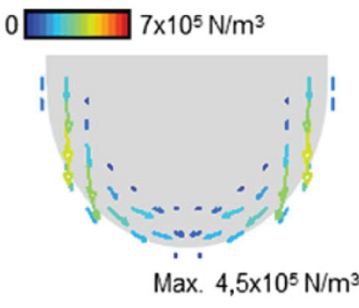

(iv) Força de arraste

(a) $170 \mathrm{~A}$

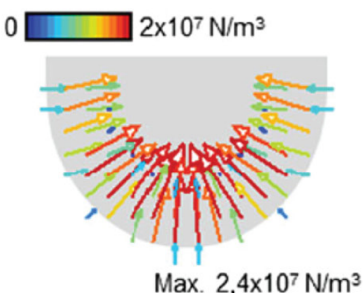

(i)Tensão superfícial

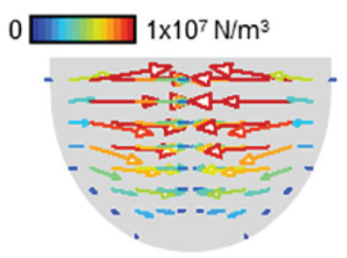

Max. $1,2 \times 10^{7} \mathrm{~N} / \mathrm{m}^{3}$

(ii)Força Eletromanética

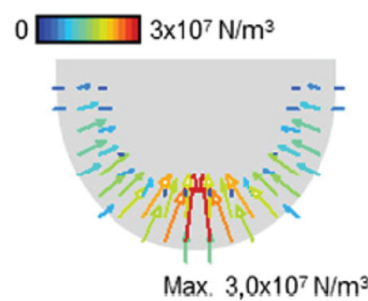

(iii) Força de expansão gasosa

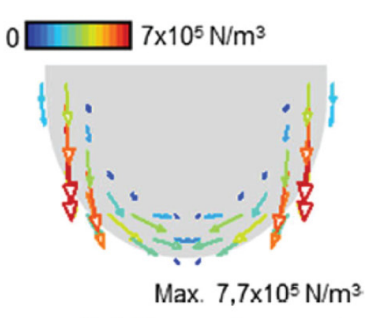

(iv) Força de arraste

(b) $250 \mathrm{~A}$

Figura 1. Ação das forças atuantes sobre a gota durante a transferência metálica. Resultados de simulação numérica para (a) Transferência globular e (b) Transferência goticular. Adaptado de Ogino e Hirata [4]. 
Os resultados obtidos por estes autores mostram que a força de arraste do gás de proteção colabora para o destacamento, porém em comparação com as demais, possui magnitude cem vezes menor e, portanto, pode ser desprezada. Do mesmo modo, à influência da força de expansão gasosa pode ser omitida, considerando que esta tem origem em microexplosões presentes na interface eletrodo-gota colaborando, assim, para o destacamento apenas em pequenos comprimentos de arco[3].

O material fundido constantemente na extremidade do eletrodo comporta-se como uma massa em expansão. Logo, sujeito à ação da gravidade. Neste sentido, a Equação 1 é frequentemente utilizada para o cálculo da força da gravidade que atua sobre a gota; onde $d_{g}$ representa o diâmetro da gota $(m), \rho$ é a densidade do material líquido $\left(\mathrm{kg} / \mathrm{m}^{3}\right)$ na região da gota e g, a aceleração da gravidade $\left(\mathrm{m} / \mathrm{s}^{2}\right)$.

$$
F_{g}=\frac{\pi}{6} d_{g}^{3} \rho g
$$

O fato de esta equação considerar somente o diâmetro da gota pressupõe que a mesma possui o formato esférico. Entretanto, segundo o modelo apresentado por Nemchinsky [5], há uma relação de dependência entre o formato da gota e as forças que sobre ela atuam, de modo que em análises experimentais ambos, formato da gota e forças que sobre ela atua, devem ser considerados simultaneamente.

Todo líquido está sujeito à ação da tensão superficial. Segundo Scotti e Ponomarev [2], esta força surge da interação molecular na superfície do eletrodo fundido e faz com que as partículas sejam direcionadas para o centro da gota. Na Equação 2, tem-se a força devido à tensão superficial $\left(F_{y}\right)$ como o produto do perímetro da gota (onde $d_{\mathrm{g}}[\mathrm{m}]$ é o diâmetro do metal líquido) por um termo chamado energia livre de superfície y [J/m²], que pode ser obtido experimentalmente para cada tipo de material e condições de operação do processo.

$$
F_{\gamma}=\pi d_{g} y
$$

De acordo com os resultados obtidos por Ogino e Hirata [4], a tensão superficial é a principal força que atua na retenção da gota sob o arame-eletrodo. Enquanto o material é fundido, sua magnitude aumenta em função do aumento do valor de $d_{\mathrm{g}}$. Entretanto, esta força é superada pela força gravitacional assim que a gota atinge um diâmetro considerado crítico, e isso define seu tamanho no instante do destacamento. Pode ser verificado ainda na Figura 1 e na Equação 2 que a ação da tensão superficial não depende diretamente da corrente de soldagem. Ainda de acordo com os resultados obtidos pelos mesmos autores, a principal força atuante sobre a gota que diferencia os modos de transferência globular e goticular é a força eletromagnética. Naturalmente, assim como o esperado e concordando com o que se observa na prática, esta é a força mais potencializada pelo aumento da corrente de soldagem e que causa o destacamento da gota antes desta atingir tamanhos relativamente grandes.

A força eletromagnética, também chamada de Força de Lorentz, surge da interação entre a corrente que está percorrendo a gota e o campo magnético gerado por essa corrente. Segundo Ogino e Hirata [4], esta força por unidade de volume é definida pela Equação 3.

$$
\vec{F}_{e m}=\vec{j} \times \vec{B}
$$

Onde, a força eletromagnética é o resultado do produto vetorial entre a densidade de corrente $\vec{j}\left[\mathrm{~A} / \mathrm{m}^{2}\right]$ e a densidade de fluxo magnético $\vec{B}[\mathrm{~T}]$.

Considerando um condutor cilíndrico, no qual a densidade de corrente é constante e atua na direção axial do mesmo, o campo magnético gerado tem formato circular e gira em torno do condutor seguindo a regra da mão direita. A partir da lei de Ampère obtemos a magnitude do campo pela Equação 4.

$$
B=\frac{\mu_{0} I}{2 \pi r}
$$

onde $I[\mathrm{~A}]$ é a corrente no condutor, $r[\mathrm{~m}]$ é a distância do centro do condutor e $\mu_{0}\left[\mathrm{~N} / \mathrm{A}^{2}\right]$ é permeabilidade magnética no vácuo. 
Segundo Young e Freedman [6], o produto vetorial garante que somente a componente da corrente perpendicular ao campo seja levada em conta. A força resultante é perpendicular tanto a corrente quanto ao campo seguindo a regra da mão direita.

Conforme visto na Figura 1, tanto a magnitude quanto a direção dos vetores da força eletromagnética são alterados dependendo da sua posição relativa à gota. Isto ocorre pois o fluxo de corrente que passa pelo arame-eletrodo flui gradativamente da gota ao arco elétrico. Este fluxo de corrente que deixa a gota irá reduzir a magnitude e alterar a direção dos vetores densidade de corrente principalmente próximo da superfície da gota, os quais não serão mais no sentido axial do eletrodo. Isto alterará a direção e a magnitude do campo magnético gerado e da força eletromagnética resultante.

Nas proximidades da parte superior da gota os vetores de densidade de corrente são maiores e estão na direção axial do arame-eletrodo, o que explica o fato de os vetores da força eletromagnética serem maiores e perpendiculares ao eixo axial do arame-eletrodo nessa região, conforme mostra a Figura 1.

No estudo da soldagem, a força eletromagnética volumétrica é descrita através de sua componente radial $\left(F_{r}\right)$ e componente axial $\left(F_{z}\right)$. Simpsom e Zhu [7] as definem em função do campo magnético e das densidades de corrente em ambas as direções, conforme as Equação 5-9.

$$
F_{r}=-j_{z} B=-\frac{\mu_{o} r}{2 \pi^{2} R^{4}} I^{2}
$$

onde

$$
\begin{aligned}
& j_{z}=\frac{I}{\pi R^{2}} \\
& B=\frac{\mu_{o} r}{2 \pi R^{2}} I
\end{aligned}
$$

onde $R[\mathrm{~m}]$ é o raio total do eletrodo na seção transversal analisada.

A partir da Equação 5 podemos observar que a componente radial da força eletromagnética aumenta com a distância ao centro da gota até a sua extremidade. Isto é devido à interação entre os infinitos campos magnéticos gerados pelos fluxos de carga passando pela gota. Conforme será visto mais adiante, o campo magnético gerado por vários fluxos de corrente dispostos simetricamente em torno de um ponto acaba por se anular no interior deste círculo, mas se somam fora dele. Com isso, o campo magnético dentro da gota será maior quanto mais afastado se estiver do centro.

$$
F_{z}=j_{r} B=-\frac{\mu_{o} r^{2}}{4 \pi R^{2}} I \frac{d}{d z}\left(\frac{I(z)}{\pi R^{2}}\right)
$$

onde

$$
j_{r}=-\frac{r}{2} \frac{d j_{z}}{d z}=-\frac{r}{2} \frac{d}{d z}\left(\frac{I(z)}{\pi R^{2}}\right)
$$

Como observado na Equação 8, a componente axial da força eletromagnética também cresce com a distância ao centro da gota, mas ela depende principalmente da variação da corrente no sentido axial. Esta variação decorre da mudança dos vetores densidade de corrente dentro da gota ocasionada pela corrente que flui gradativamente ao arco elétrico.

Para valores de corrente acima da transição, a força radial é muito intensa na região de acoplamento da gota, como visto na Figura 1. Nesta magnitude, ela é capaz de deformar a gota e gerar uma constrição na região de acoplamento gota-arame, o que aumenta a magnitude dos vetores densidade de corrente e cria duas regiões desses vetores: uma de convergência e outra de divergência, acima e abaixo da constrição, respectivamente. 
Nemchinsky [5] afirma que a força axial $\left(F_{z}\right)$ depende da distribuição de corrente no interior da gota, sendo que ela atua no sentido de manter a gota junto ao arame-eletrodo com linhas de corrente convergentes e destaca a gota com linhas de corrente divergentes. Isto ocorre porque o produto vetorial dos novos vetores densidade de corrente, com o campo magnético, irá gerar forças axiais que tenderão a deslocar a gota para baixo e o restante do material fundido para cima (Figura 2).

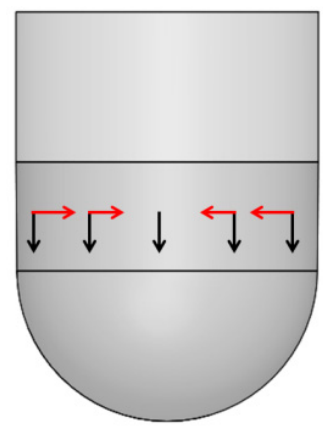

(a)

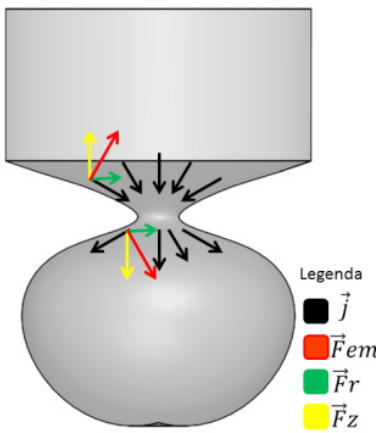

(b)

Figura 2. (a) Forças radiais geradas na gota sem a presença da estricção, e forças radiais e axiais geradas pela presença da estricção (b), ambas em um corte no plano médio da visualização.

Este é o princípio do destacamento da gota no modo de transferência goticular, onde a gota é "estrangulada" pela componente radial e direcionada para a poça pela força axial, com seu tamanho ainda reduzido. Amplificar estas forças significa estimular este fenômeno e, teoricamente, alcançar o modo de transferência goticular com menores densidades de corrente. $\mathrm{O}$ meio mais direto para se atingir este objetivo sem alterar a corrente de soldagem é aumentar o campo magnético que atua sobre a gota.

Deste modo, este trabalho tem como objetivo propor e avaliar a viabilidade de um dispositivo com o intuito de gerar campos magnéticos auxiliares na região do arco voltaico, os quais interajam com a corrente que atravessa a gota e intensifiquem as componentes da força eletromagnética nela presente. Com isso, busca-se promover o destacamento da gota com tamanho reduzido mesmo empregando baixos valores de corrente, compatíveis com aqueles utilizados no modo de transferência globular. Assim, espera-se que o menor aporte de energia sobre a peça colabore para a soldagem de chapas finas com uma transferência estável sem a necessidade do emprego de fontes de soldagem mais complexas e de maior custo.

\section{Dispositivo para Geração de Campo Eletromagnético}

Um campo magnético pode ser obtido por um imã permanente ou pelo fluxo de corrente elétrica em um condutor, sendo o formato do mesmo crucial para o estabelecimento da direção das linhas de campo magnético. Visando obter um maior controle sobre a magnitude dos campos magnéticos produzidos, a utilização de indutores torna-se uma saída interessante visto que o campo é diretamente influenciado pela magnitude e sentido da corrente que percorre o condutor.

A fim de criar campos magnéticos suplementares àqueles auto induzidos na gota, e que atuem no mesmo plano destes, torna-se adequado, portanto, o uso de indutores retilíneos. Com base nas Leis de Gauss, os indutores retilíneos geram um campo magnético circular em torno do seu eixo, onde o seu sentido segue a regra da mão direita.

A interação magnética resultante entre dois condutores retilíneos e paralelos pode ser de atração no caso das correntes estarem no mesmo sentido, ou de repulsão com uso de sentidos opostos de corrente [6]. Portanto, sugere-se o emprego de correntes nestes indutores com sentidos opostos ao da corrente que atravessa o arame-eletrodo. Desta forma, busca-se que os campos magnéticos gerados pelos indutores se somem ao campo magnético natural gerado pelo arame-eletrodo, onde a força de repulsão gerada intensifique o estrangulamento da gota. 
Isto posto, foi idealizado um dispositivo, cuja concepção é mostrada na Figura 3, onde os indutores retilíneos são dispostos de forma equidistante ao arame-eletrodo, visando o equilíbrio do campo magnético em relação ao eixo axial do arame-eletrodo.

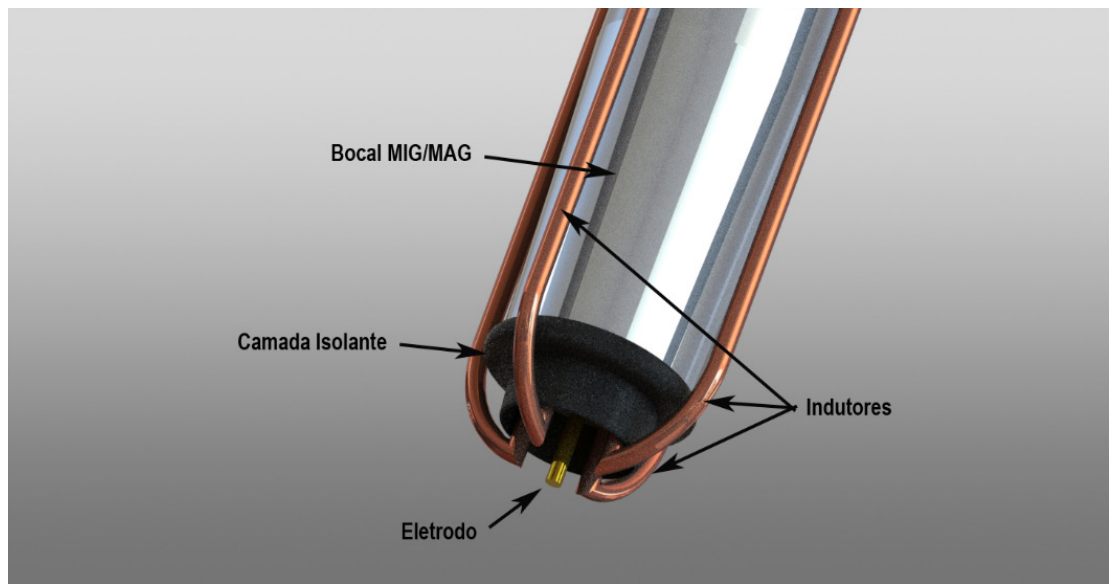

Figura 3. Concepção do dispositivo de geração de campos magnéticos auxiliares para a soldagem MIG/MAG.

A região de atuação do presente dispositivo compreende a parte interna ao bocal de gás, onde a corrente passa no sentido contrário ao da corrente de soldagem (no arame-eletrodo) gerando, portanto, a força de repulsão. A fim de fechar a malha de corrente do circuito elétrico, os indutores passam externamente ao bocal de gás retornando à fonte de alimentação. Como a corrente presente no lado externo dos indutores possui o mesmo sentido que a corrente no arame-eletrodo, faz-se necessário o uso de uma camada isolante magnética que evita as interações eletromagnéticas entre a parte interna e externa do indutor. Além disso, com o intuito de evitar a indução de correntes parasitas no arame-eletrodo devido à variação no campo magnético externo, este dispositivo deve operar somente com corrente contínua. Na Figura 4 é apresentado o sentido real das correntes no arame-eletrodo e nos indutores.

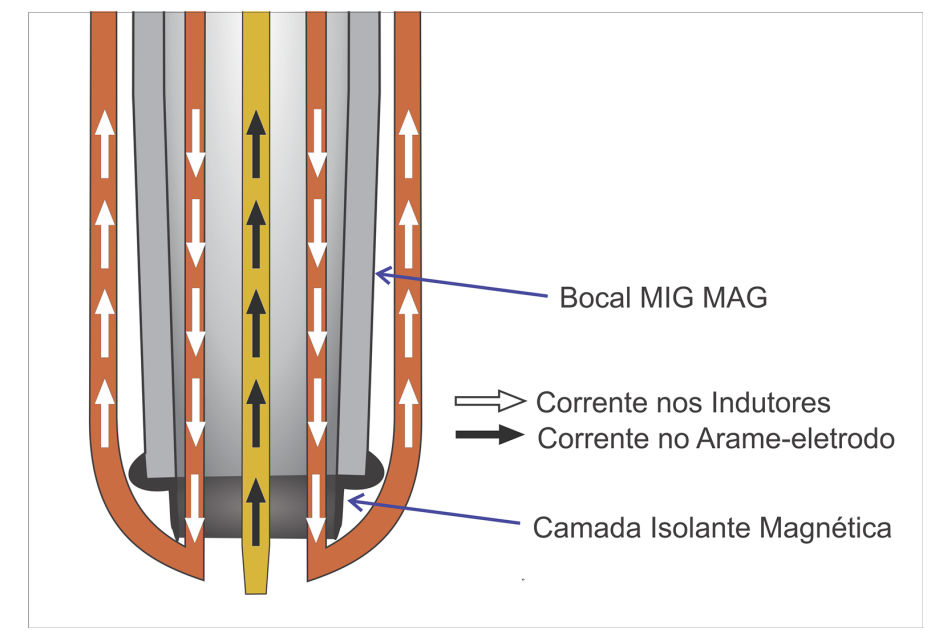

Figura 4. Relação entre correntes do arame-eletrodo e indutores.

Os campos magnéticos gerados tanto pelo arame-eletrodo quando pelos indutores foram modelados e somados a fim de obter os campos magnéticos resultantes. Desta forma, variando-se a magnitude da corrente elétrica aplicada nos indutores (Equação 4), foi possível verificar a interação entre esses campos. A Figura 5 apresenta uma imagem ampliada da seção do campo transversal aos indutores (4 indutores), cada um sendo percorrido por uma corrente constante de 250A a uma distância de $4 \mathrm{~mm}$ em relação ao arame-eletrodo. Os eixos representam a distância do centro do indutor. 


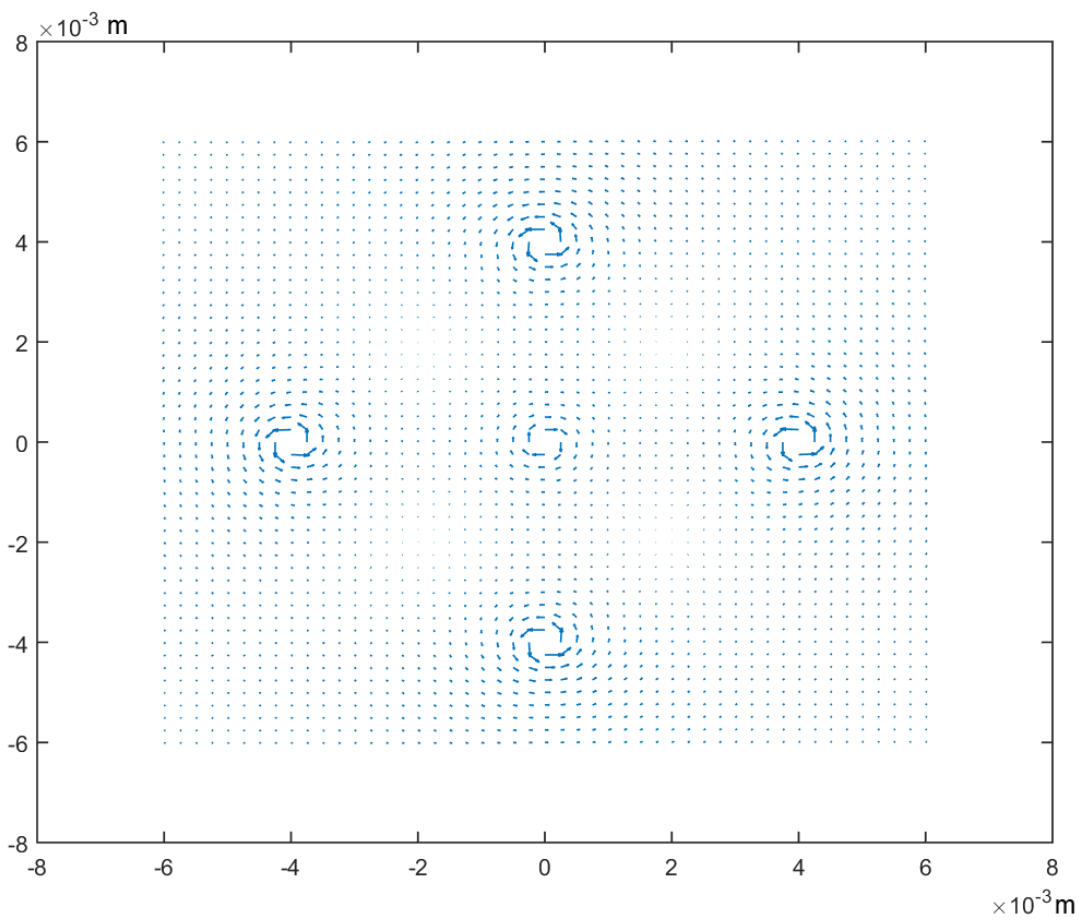

Figura 5. Campo magnético induzido por 4 indutores cada qual sendo percorrido por uma corrente de $250 \mathrm{~A}$.

Com o intuito de avaliar a efetividade do dispositivo proposto, foi analisado o seu efeito para diferentes quantidades de indutores dispostos radialmente em torno do arame-eletrodo e a corrente aplicada nos mesmos. Os campos induzidos foram então comparados com aqueles produzidos no arame-eletrodo na transferência goticular e globular. Para o estabelecimento das correntes nos modos goticular (250 A) e globular (170 A), foram tomados como base os valores usados por Ogino e Hirata em suas simulações [4].

Para a simulação dos campos obtidos pelos indutores, a corrente no arame-eletrodo (corrente de soldagem) foi fixada em $170 \mathrm{~A}$ e a corrente dos indutores foi variada, buscando um campo magnético resultante superior àquele obtido na transferência goticular natural na região da gota. $O$ resultado desta simulação é apresentado na Figura 6 , onde a média aritmética dos módulos dos vetores do campo magnético é obtida na área de interesse, (cerca de $0,6 \mathrm{~mm}$ de distância do centro do eletrodo) contemplando, assim, o campo que interage com um eletrodo de $1,2 \mathrm{~mm}$ de diâmetro.

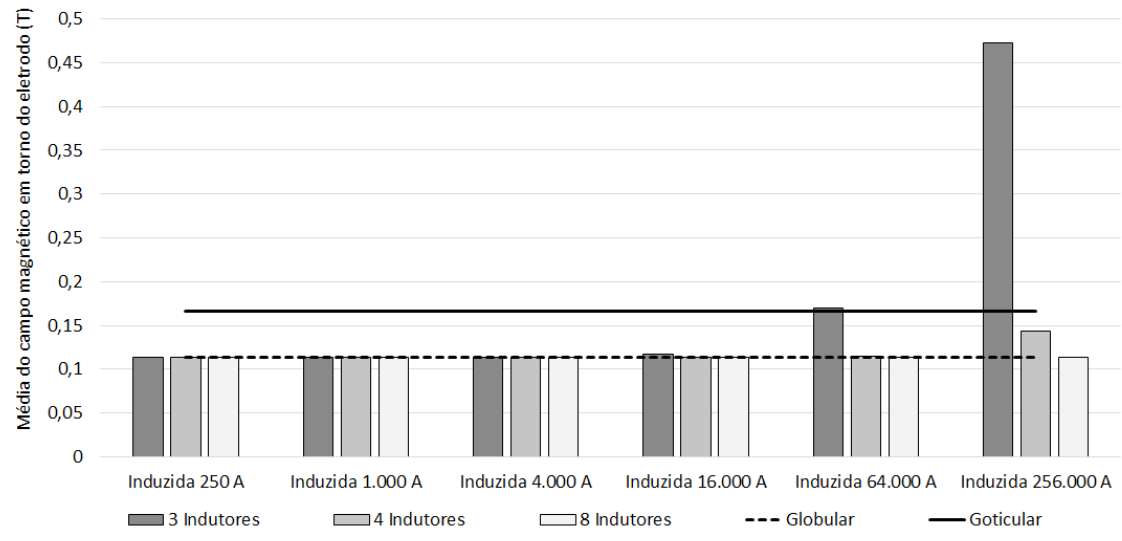

Figura 6. Comparação dos campos auxiliares induzidos com os campos obtidos nas transferências goticular e globular. 
Conforme pode ser visto, somente correntes nos indutores acima de $16.000 \mathrm{~A}$, aproximadamente, surtiram efeito sobre o campo em interação com o arame-eletrodo. Ainda assim, estes valores não atingiram o patamar de campo necessário para a obtenção da transferência goticular. De fato, isto somente foi conseguido com o emprego de correntes nos indutores acima de 64.000A, aproximadamente, e com um número menor de indutores. Este resultado, que a priori parece ser contraditório, de fato, se mostra coerente. Na verdade, quanto menor o número de indutores, mais significante é a ação do campo magnético induzido comprovando, assim, a Lei de Gauss, que expõe que o campo magnético dentro de uma superfície fechada, com presença de corrente elétrica, é nulo devido à interação entre campos de sentidos opostos.

Pela Equação 3, nota-se que o campo magnético adicional obtido com o dispositivo proposto deve apresentar maior magnitude que aquele gerado naturalmente no modo de transferência goticular. Visto que para obtenção da mesma magnitude de força atuante sobre a gota os valores de campo magnético deverão equilibrar os menores valores de corrente de soldagem propostos para o arame-eletrodo. Portanto, utilizando os valores médios de corrente de soldagem e campo eletromagnético é possível relacionar um valor médio de campo necessário para a obtenção de uma transição de transferência globular para goticular em correntes inferiores de soldagem quando utilizado os indutores propostos.

Interpolando linearmente os resultados em que a indução interferiu no campo magnético, durante a simulação para três indutores foi possível obter um valor médio de corrente necessário nos indutores. $\mathrm{O}$ valor obtido foi de aproximadamente $114.000 \mathrm{~A}$ (Figura 7).

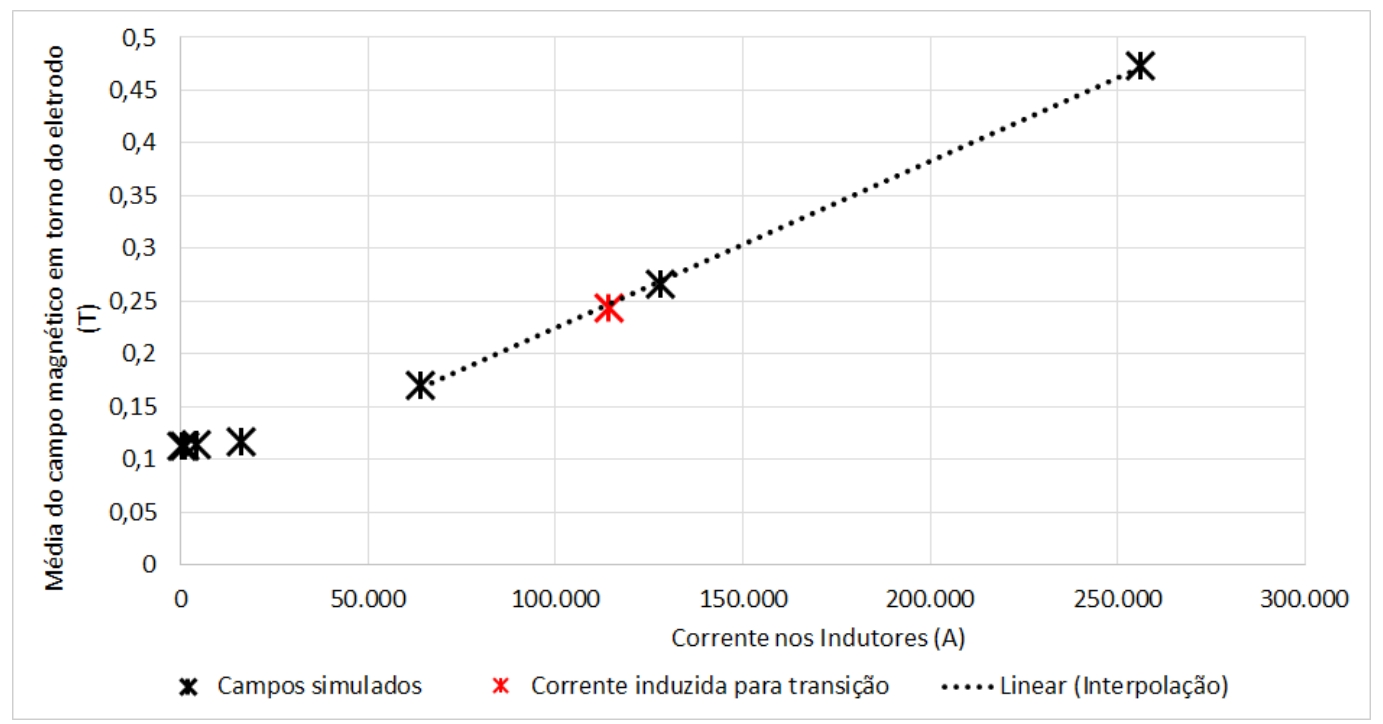

Figura 7. Interpolação dos campos para 3 indutores.

A Figura 8 representa uma seção do campo transversal aos indutores, abrangendo a área de interesse para a configuração de três indutores, com corrente de $10.000 \mathrm{~A}$ e distância entre o arame-eletrodo e os indutores de $4 \mathrm{~mm}$. Esta corrente foi escolhida para representação já que a simulação para a corrente de 114.000A resulta numa distribuição extremamente complexa dos campos de modo que inviabiliza a visualização das posições originais dos indutores. Os eixos representam a distância a partir do centro do eletrodo, sendo assim, é possível verificar que os indutores não aparecem nesta vista aproximada na região de interesse. Nesta simulação, os indutores estão posicionados nos vértices de um triângulo equilátero hipotético com um dos vértices centralizado na parte superior da imagem a $4 \mathrm{~mm}$ do centro.

Analisando a Figura 8 é possível verificar a geração de instabilidade no campo magnético, esta ocorreu para as três configurações com 3, 4 ou 8 indutores. Isto se deve ao fato de que o campo não apresenta uma distribuição radialmente uniforme em torno do arame-eletrodo. Deste modo, podendo gerar instabilidades não indicadas ao processo de soldagem à arco possibilitando, assim, a formação de respingos e mal direcionamento do arco voltaico sobre a peça. 


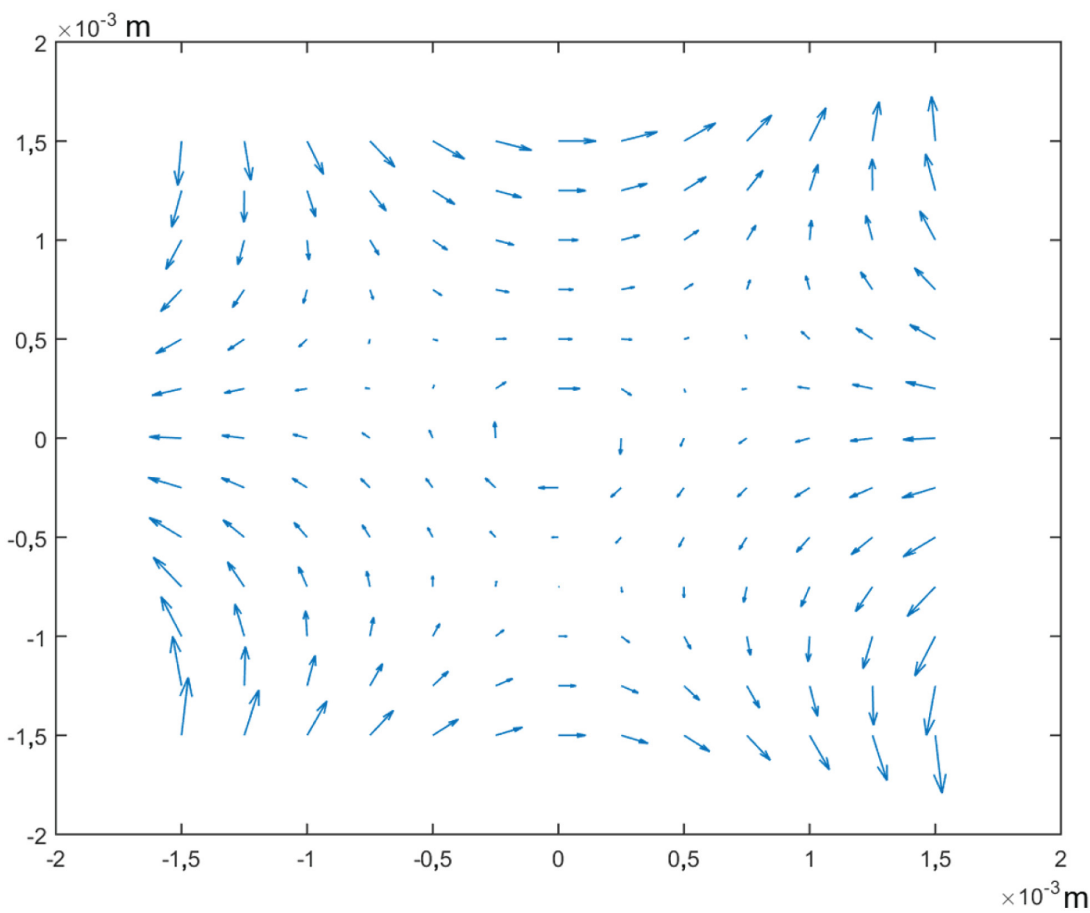

Figura 8. Campo magnético induzido por 3 indutores com corrente de 10.000A, distância de 4 mm entre indutor e eletrodo.

\section{Conclusão}

Pela análise dos resultados obtidos por simulação numérica, podemos concluir que a proposta de criar campos magnéticos externos com o intuito de auxiliar o processo de destacamento da gota no processo MIG/MAG é possível. Entretanto, isto não se mostrou tecnologicamente viável dado ao fato de somente com valores de corrente extremamente elevados, da ordem de 100.000A, se consegue gerar campos magnéticos auxiliares com a magnitude suficiente para destacar as gotas em pequenas dimensões do arame-eletrodo. Além disso, foi verificado que não somente a intensidade de corrente nos indutores deve ser considerada, mas também, o número de indutores a ser empregados no dispositivo. Pois isto tem influencia direta no comportamento do campo magnético resultante em torno do arame-eletrodo, acarretando numa distribuição radial não uniforme. Neste sentido, melhores resultados teóricos foram obtidos com uma menor quantidade de indutores.

\section{Agradecimentos}

Os autores agradecem ao CNPq pelas bolsas de pesquisa, ao Dr. Diogo Nardelli Siebert e Dr. Luis Orlando Emerich dos Santos pelo imprescindível auxílio na elaboração do estudo.

\section{Referências}

[1] Kah P, Latifi H, Suoranta R, Martikainen J, Pirinen M. Usability of arc types in industrial welding. International Journal of Materials Engineering. 2015;15:2-12.

[2] Scotti A, Ponomarev V. Soldagem MIG/MAG: melhor entendimento melhor desempenho. São Paulo: Artliber; 2008.

[3] Wainer E, Brandi SD, Mello FD. Soldagem: processos e metalurgia. 7. Ed. São Paulo: Blücher; 2010.

[4] Ogino Y, Hirata Y. Numerical simulation of metal transfer in argon gas-shielded GMAW. Welding in the World. 2015;59(4):465-473. http://dx.doi.org/10.1007/s40194-015-0221-8.
[5] Nemchinsky VA. Size and shape of the liquid droplet at the molten tip of an arc electrode. Journal of Physics. D, Applied Physics. 1994;27(7):1433-1442. http://dx.doi.org/10.1088/0022$3727 / 27 / 7 / 014$

[6] Young HD, Freedman RA. Fisica III: eletromagnetismo. 12. ed. São Paulo: Pearson; 2009. 425 p.

[7] Simpson SW, Zhu P. Formation of molten droplets at a consumable anode in an electric welding arc. Journal of Physics. D, Applied Physics. 1995;28(8):1594-1600. http://dx.doi.org/10.1088/0022$3727 / 28 / 8 / 008$. 